\title{
ANTHROPOLOGY
}

Deren Ceker, ${ }^{1,2,+}$ M.Sc.; and William D. Stevens, ${ }^{3,4}$ M.A.

\section{Recovery of Missing Persons in Cyprus: Heavy Equipment Methods and Techniques for Complex Well Excavations*}

\begin{abstract}
This technical note presents the methods and techniques developed by the Bi-communal Forensic Team (BCFT) of the Committee on Missing Persons in Cyprus (CMP) used to excavate and exhume the remains of missing persons, many of whom were buried in deep wells at sites across the island of Cyprus during the conflict period of the 1960s and 1970s. A total of 493 Turkish Cypriots and 1508 Greek Cypriots were officially reported missing by the two communities as a result of the conflict. Since the team's formation, in 2005, the BCFT has excavated 114 wells, resulting in the recovery of 195 missing individuals from 35 of these well excavations. The standard excavation approach used by the BCFT, especially for deep well recovery, consists of "ramp," "pocket," and "pool" components. These excavation features enable CMP archaeologists to excavate deep wells safely and efficiently while simultaneously permitting time for thorough documentation and unimpeded recovery of human remains. The team uses three variants of this approach to cope with the variety of geological, physical, and hydrological contexts faced in Cyprus' wells, including hard and soft landforms, the presence or absence of water, and limitations imposed by surrounding infrastructure. The "terracing", "double-ramp", and "single-ramp" variations are detailed with respect to the environmental contexts which prescribe their use. The BCFT's general procedures for human remains recovery and standard well safety protocols conclude the article.
\end{abstract}

KEYWORDS: forensic science, forensic archaeology, forensic anthropology, excavation of wells, Committee on Missing Persons in Cyprus, exhumation, excavation machinery

The Bi-communal Forensic Team of the Committee for Missing Persons (CMP) has been conducting well and nonwell excavations since 2005 , as part of the effort to find persons reported missing as a result of the conflicts of 1963 to 1964 and 1974. A total of 493 Turkish Cypriots and 1508 Greek Cypriots were officially reported as missing by both communities. Over a period of nine years, 114 wells have been excavated by the BCFT, and from these, 195 individuals have been recovered from 35 deep well excavations. The wells of Cyprus present a unique context both due to their depth and structure, and to the frequency with which they were used for the purpose of disposal of remains. The country presents an abundance of abandoned or disused wells, making them an easy and obvious choice for hasty or clandestine disposal of human remains during the conflict period. Considering the degree of experience of the CMP in well excavation and the relative paucity of scientific publications on well excavation methods in the literature, it is important to outline the methods and techniques developed by the BCFT. This article presents the first detailed publication of standardized

\footnotetext{
${ }^{1}$ Archaeology and History of Art, Bilkent University, Ankara, Turkey.

${ }^{2}$ Department of Anthropology, Ankara University, Ankara, Turkey. $\mathrm{SC}$.

${ }^{3}$ Department of Anthropology, University of South Carolina, Columbia,

${ }^{4}$ Richland County Coroner/Medical Examiner's Office, Columbia, SC.

${ }^{\ddagger}$ Present address: CMP Anthropological Laboratory, UN Buffer Zone, Nicosia, Cyprus.

*Presented at the 64th Annual Meeting of American Academy of Forensic Sciences, February 20-25, 2012, in Atlanta, GA.

Received 24 Mar. 2014; and in revised form 12 Oct. 2014; accepted 23 Oct. 2014
}

methods via coordinated human labor and heavy equipment for the excavation and recovery of human remains from deep wells. In doing so, we describe the general method and techniques for well excavation developed by the BCFT which are in use for the excavation and recovery of the remains of missing persons across Cyprus.

\section{Background-Forensic Archaeology of Wells}

The disposal of bodies in wells is certainly not unique to Cyprus and has taken place throughout human history. For obvious reasons of convenience of use for disposal and perceived inaccessibility for discovery and recovery, the choice of wells for clandestine burial is common. Wells and similar structures such as privies are recognized by archaeologists as frequent contexts for the disposal of human remains (1-4). From a forensic archaeological perspective, wells are included within the classification of clandestine burials and mass graves $(5,6)$. Within the context of armed conflict, war, and genocide, the disposal and subsequent recovery of bodies from wells by forensic teams is documented in Guatemala (7,8), Paraguay (9), Turkey (10), Croatia (11-13), Bosnia-Herzegovina (14), and in Afghanistan (15). Deaths occurring in wells in addition to the disposal of human bodies in wells present a domestic problem for law enforcement agencies and medico-legal entities worldwide. See Hochrein and Roberts (16) for an excellent summary of media accounts of criminal disposal of bodies in wells in the United States as well as historical discussion of well-disposal of bodies. The literature from Turkey presents death and discovery of bodies in wells from a public health and safety viewpoint as well 
as a forensic pathology perspective citing the danger presented by open wells and the difficulty of determining identity and cause of death of individuals recovered from wells $(17,18)$. Magni et al. (19) illustrate similar challenges in Italy as well as the ability of taphonomic variables in well environments to hinder the determination of postmortem interval and the great difficulty of body retrieval from wells. The unique taphonomic variables created by wells as well as factors such as commingling and the challenges of trauma interpretation create complex scenarios for forensic investigators $(12,20)$. Levine et al. (21) published the first detailed account of a case study of forensic excavation and recovery of a body from a well context. In their case, careful bisection and stratigraphic excavation of the well using both heavy machinery and manual labor permitted controlled recovery of a body and associated artifacts and evidence in an expeditious manner. Hochrein and Roberts (16) proposed an efficient and easily implemented method for three dimensional mapping of human remains and evidence in well contexts using a polar coordinate system.

\section{Setting up the Excavation Plan}

The general approach to well excavation used by the CMP is standardized, but excavation strategies and methods are left flexible in order to effectively confront the many variables associated with well excavation and recovery. CMP forensic archaeologists make excavation planning decisions as the result of careful consideration of the type of well, the depth of the well, and of the hydrology of the area and the morphology of the soil surrounding the well. The team has developed three variations on the general approach, which are effective in addressing the variety of contexts found among Cyprus' wells. These variants will be discussed in the next section. The depth of the wells excavated so far by the BCFT ranges from 5 to 31 meters.

The well excavation process always begins by gathering historical and circumstantial data related to the missing person(s), and information about dominant land forms, land use, and the geomorphology of the excavation area. The team gathers information about the depth of the well from the witness(es) of the case or from local villagers to assist in developing a safe and efficient excavation plan. The three most important questions that need to be addressed in developing the excavation plan are listed and explained as follows.

\section{What is the dominant landform surrounding the well?}

Gonno (hardpan soil/clay), havara (lime stone), bedrock, and sand are the most common soil types in Cyprus. The BCFT considers the dominant landform in selecting the extra equipment that will be used in conjunction with the excavating machines to hasten the excavation process. For example, the hydraulic breaker is used for bedrock or hard sediment, and the ripper hook, which is attached to the dipper arm (hand) of the tracked excavator, is used for havara soil. Hastening the process is not only important for economic concerns, but it is critical for safety because the excavated soil surrounding the well loses its humidity and stability, becoming increasingly dangerous.

\section{Is it a dry well or a wet well?}

This is very important because the proper method for a dry well is changed when the water is found. This is a critical consideration because the risk of a potentially lethal collapse is greater if there is water in the well. Thus, knowing the depth of the well, the presence or absence of water, and the type of soil surrounding the well, the BCFT archaeologists establish the best excavation plan based on the data at hand, which also includes the selection of the type of heavy machinery that will best serve the excavation.

\section{What is the depth of the well?}

Keeping in mind that all wells are capable of collapsing and that the risk increases with depth of excavation, knowing the depth of the well is of paramount importance when formulating the excavation plan. Knowledge of an approximate depth permits the team to quickly select the appropriate machinery and excavation methods. The working plan should always accommodate for the fact that expected well depth is often underestimated. When the depth is not known by the witness(es), the information can be gathered from the municipality of the village or the native villagers who may also have similar wells in their own fields. The wells are dug based on the subterranean water table levels of the local area; therefore, wells in neighboring fields should have approximately the same depth.

\section{Excavation Process}

When conducting a deep well excavation, it is the standard practice of the BCFT to remove, by excavation, the sides of the well shaft and to construct an access ramp on one side which enables heavy machinery and team members to reach the base of the well simultaneously (Fig. 1). A tracked excavator breaks the hard ground around the mouth of the well and creates an access ramp with the assistance of a wheel loader, which can transport large amounts of loose soil out of the excavation area. The well is opened on minimally three sides (four if possible), not only for safety and speed, but also to allow access for the team to recover remains and additional evidence in situ. A "pocket" depository platform is opened next to the well for manual screening of the fill from the well. The "pocket" is simply a flat excavated area next to the well shaft where fill can be placed (Fig. 2). The tracked excavator does not disturb the sediment inside the well during the excavation. Archaeologists check the soil manually for remains inside and outside of the well. Wet or dry screening is conducted based on the presence or absence of water.

An important detail to note is that as the excavation of the well gets deeper and the ramp level correspondingly lowered, the tracked excavator is required to excavate the mouth area of the well. As this takes place, a considerable amount of soil collapses inside the well, causing the last excavation depth checked for remains by the archaeologists to be lost. To avoid potential loss of data, the excavation team places indicators such as wooden sticks surrounded with safety bands in the well at that level so that it may be relocated. The ripper hook which is attached to the dipper arm of the tracked excavator is used for well mouth areas with surrounding limestone. It is more efficient for breaking limestone than other machinery and works well in conjunction with a wheeled loader which can remove limestone fragments in its scoop. Dump trucks are used to increase the speed of soil transport and can easily work on the ramp if the angle of the ramp was suitably planned prior to excavation. While backhoe loaders are typically used by the BCFT for shallower wells having a depth in the range of 9-10 m, they can also be used at deep well excavations to make the well mouth 


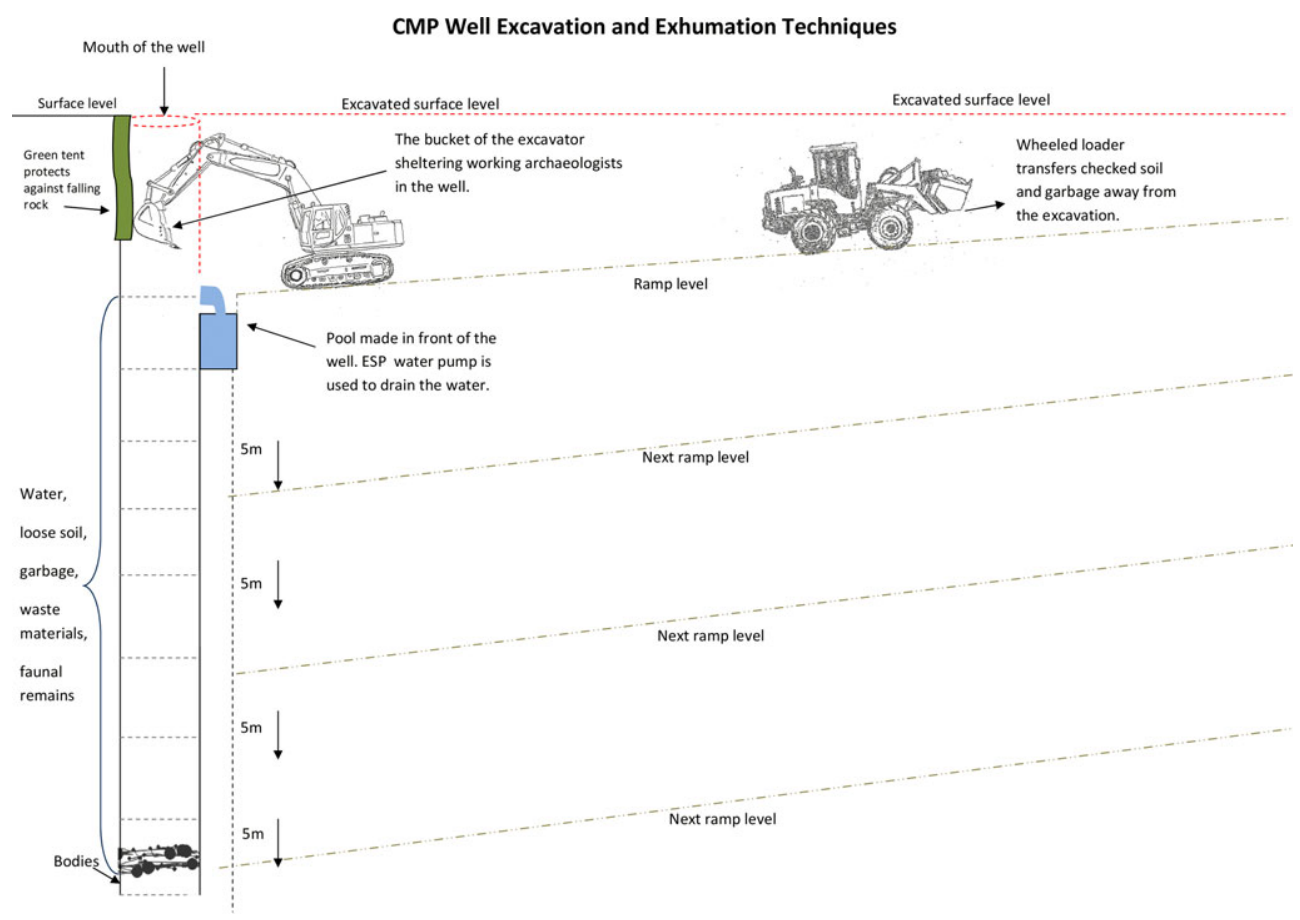

FIG. 1-Standard practice of the BCFT for deep well excavations. Sketch showing an access ramp on one side which enables heavy machinery and team members to reach the base of the well simultaneously



FIG. 2-Picture showing the pocket depository platform made by tracked excavator, next to the well shaft where fill can be placed.

more secure by enlarging it, excavating it at an angle, and moving loose soil away from its edges.

As a well excavation progresses, measurements of its depth require increasing care and accuracy. For example, CMP archaeologists put marks on the wall of the well indicating the depth every 4-5 m. These marks can be made using metal pins and marked with colored spray paint on the wall of the well. This obviates the need to measure depth every day, thereby minimizing risk to the team. Additionally, all the measurements remain reliable even if the mouth of the well, which represents the ground level, needs to be removed.

\section{Setting up the Excavation Methods}

There are three basic methods developed and used by the CMP archaeologists for coping with the three different dominant landforms, as well as the hydrology of the area, and other physical or environmental constraints encountered in the vicinity of Cyprus' wells:

- The Terracing method: This method was created to reduce the risk of soil erosion and collapse during soft landform excavations and was first used at the Akdogan-Lisi Well, in the northern part of Cyprus in 2009. The approach involves creating terraces all the way around the mouth of the well as well as covering the ramp area. The mouth of the well is opened on three sides, and an access ramp is constructed on one side. Terraces are made beginning from the mouth of the well up to the end of the ramp (Fig. 3). The access ramp is then extended downward as the well excavation proceeds. The deposits from the well are placed on the pocket, which is made next to the mouth of the well, and then manually screened. After checking, the fill is trucked off-site for safety and to make space, so that the access ramp can be deepened and the sediments placed on the depository platform. In addition to the previously described features, steps are often made in front of the well, in order to permit access and to facilitate work at the burial level.

- The Double-ramp method: This method was created to excavate a 22-meter-deep wet water well with a continuous flow of water at Gokhan-Voni Village in 2008. Two access ramps are made in this type of well excavation, one for heavy machinery and the other to serve as a pocket or depository platform to screen muddy soil from the well, and also for water transfer (Fig. 4). These types of wells continually fill with water during excavations, despite the constant use of electrical submersible pumps (ESPs), making it difficult or impossible for archaeologists to work at the burial level. To address the water flow problem, the team uses a system including a pool made in front of the well to change the direction of water flow and divert water from the well 


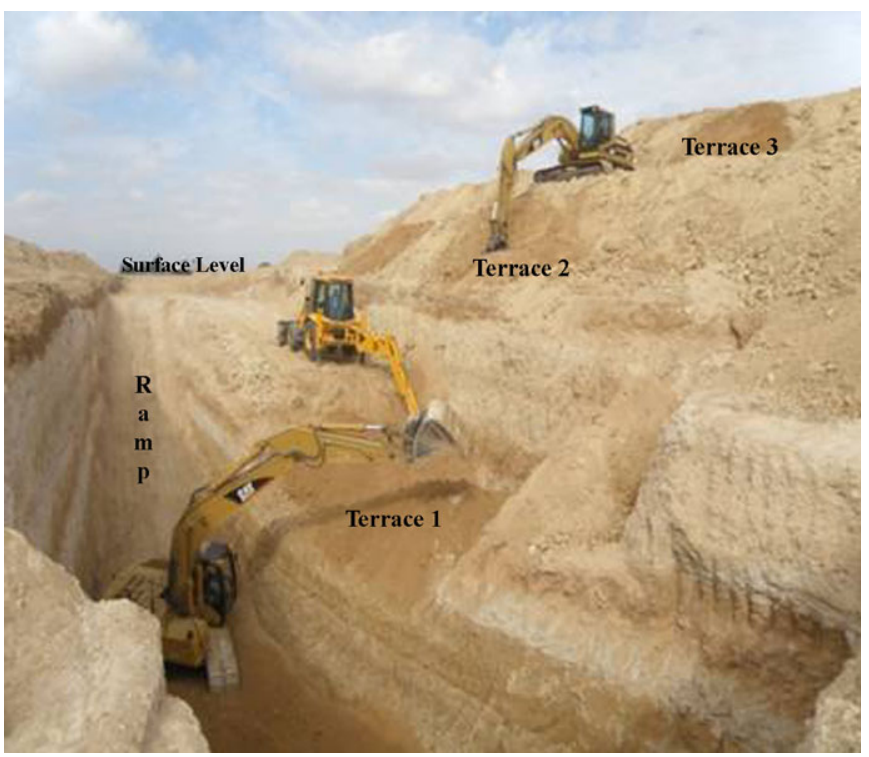

FIG. 3-Terracing method as applied to the soft landform of Akdogan-Lisi Well excavation, in the northern part of Cyprus (2009).

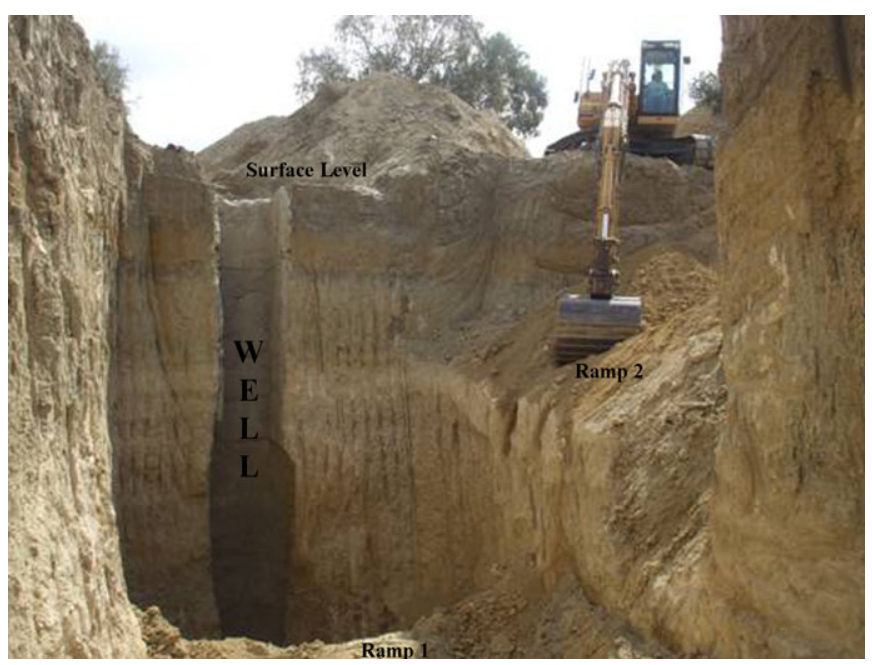

FIG. 4-Double-ramp method that was created to cope with the continuous flow of water of the well at Gokhan-Voni Village, in the northern part of Cyprus (2008).

deposit. The depth of many of Cyprus' wells makes it difficult for the pumps to draw water from the water level to ground level so the team often uses metal barrels as intermediate water tanks. Water is pumped into the barrel which is placed at half the distance from water level to ground surface and pumped from there the remainder of the distance up to ground level. The excavation team typically divides into two groups during this type of excavation. One group of archaeologists descends into the well, simultaneously draining the water out and manually checking for remains, while the other group checks the fill as it is placed into the pocket by the tracked excavator.

- The Single-ramp method: This excavation method was developed as a variant of the double-ramp method to excavate a 31-m-deep water well at Iskele-Trikomo Village, in 2010. The single-ramp method was developed both to cope with a dominant limestone and hard clay landform and to address challenges of space limitation in the context of a deep wet well. The original excavation was limited by the presence of streets and residential houses on the site, bounding the well site completely. Due to the confined site area, the team developed the system of an access ramp and a pocket, excavated adjacent to the mouth of the well. A tracked excavator, a wheel loader, and a truck are typically used in this type of excavation. A hydraulic breaker is attached to the excavator in order to loosen the compact sediments of the area. The wheeled loader is used to level the access ramp and to transfer sediments from the deeper end of the ramp, toward the top, and onto the ground surface. The sediment is then loaded into a dump truck to be deposited off-site. Team members descend into the well, taking turns as they fatigue, to excavate the remains when they are encountered. The fill around and under the bodies is placed in the bucket of the tracked excavator and transferred to the pocket made on the access ramp for screening. Wet-screening is usually necessary to insure complete recovery in these scenarios.

\section{Exhumation Process}

According to the standard operating field procedures of the BCFT, burials are classified as single (one body), multiple (up to four bodies), and mass burials (those containing five bodies or more). In each of these contexts, the use of a grid system, thorough data recording, and systematic photography is imperative. After the human remains are located, the limits of the well are extended with the bucket of the tracked excavator. This is made because ample space is required to avoid trampling and damaging the bones. For safety, the walls of the well are cut from three corners, if possible, in " $V$-shape" formation that is wider at the top and narrower at the base, having $45^{\circ}$ sloped walls prior to the start of manual work in the well. Because the skeletal remains in the well are usually superimposed and compressed, the archaeologists are very careful to delineate anatomically articulated bones in order to separate complete individuals from commingled bone masses. The archaeologists separate individual remains by tagging them with different colored bands.

Inevitably, there are some well scenarios which make it impossible to open more space or excavate mechanically, requiring excavation team members to be lowered into the well with the use of appropriate safety equipment and under the supervision of emergency rescue authorities. Physical and mental strength, coupled with awareness, concentration skills, and strong knowledge of human osteology and forensic archaeological techniques, are thus requisite for members of the team who excavate wells. Because the well excavation teams have to work under difficult and confining conditions within very deep and narrow spaces, they have to work as quickly and efficiently as possible due to safety risks.

\section{Safety during Excavation}

All well excavations have a potential to collapse, and the risk becomes greater when there is heavy machinery at the surface, when removed soil is piled near the edge of the excavation, after heavy rainfall, or if there is water inside the excavation trench. Because of these hazards, whenever possible, excavations should be dug with slopes or steps all the way around. In situations where this is not possible, due to imposing structures such as roads, houses, and utilities, the situation needs further evaluation to assure that the risk of collapse is minimized. The BCFT 
follows universal construction work standards including hard hat and protective boot and glove-use, bright, reflective clothing, and communication via walkie-talkies.

Safety is the foundation of our excavation methods. The first method involves opening a trench at $45^{\circ}$, creating a " $V$-shape" formation all around the burial area. The second method is creating terraces (for wells) or steps (for open field excavation) all the way around the burial area. Each step, including both height and width (rise and run) of the stepping area, should not be less than two meters. Terraces are created to avoid collapse of soft soil and are constructed based on an angle. The height and the width of the terraces are determined based on soil composition and hardness. In addition, the terraces for wells should be wide enough to allow easy access for heavy machines and also to traverse $360^{\circ}$ while working. As soil is removed, it should be placed at least three to four meters away from the edge of the terrace. Ramps should be wide enough to allow easy access, even when the digger is in place. This is vital in case an emergency occurs and personnel must enter the area, or so that the ramp will not be completely sealed in the event of a collapse. As the well deepens, the loose soil should be placed farther away from the edge. The best practice is to keep loose soil far away from the excavation area.

The approach to entry and exit of the well by team members is an important issue as working inside the well. Properly secured ladders can be used in order to enter or exit wells, but in some cases, they become dangerous if the wall that the ladder is secured to loses its stability. The bucket of an excavator can be used as a lift and is a more secure and quick way for the archaeologists to enter or exit the deep wells, especially when there is water which can make a ladder unstable. A mesh is sometimes placed on the walls of the well to stop debris from falling, but it becomes useless when the well is deep. The excavator's bucket also serves as a shelter, protecting the archaeologists against falling rocks. The bucket can also be used to quickly extricate workers in case of danger.

\section{Conclusions}

Over the past nine years, the CMP Bi-communal Forensic Team has formulated their own general approach and developed specialized techniques for excavating deep wells which enable safe and efficient excavation and recovery of human remains. These methods enable team members to excavate wells of all types and depths safely and successfully, while maintaining the provenience of recovered evidence and reducing excavation time period and cost. In doing so, CMP forensic archaeologists overcome archaeological, logistical, and physical difficulties to reach the human remains of individuals that went missing as a result of the conflicts, across Cyprus during the 1960s and 1970s.

\section{Acknowledgments}

We are grateful to the Committee on Missing Persons in Cyprus Turkish Cypriot member Mrs. Gulden Plumer Kucuk, Greek Cypriot member Mr. Theophilos V. Theophilou, and the Third Member of the United Nations Paul-Henri Arni for allowing and encouraging the publication of this article. We are also deeply indebted to the Bi-communal Forensic Team members who worked in these well excavations. This article would not have been possible without their help, support, and encouragement. Funding provided by the Committee on Missing Persons in Cyprus.

\section{References}

1. Brothwell DR. Digging up bones: the excavation, treatment, and study of human skeletal remains. London, U.K.: Trustees of the British Museum, 1965.

2. Burnston SA. Babies in the well: insight into deviant behavior in eighteenth century Philadelphia. In: Poirer DA, Bellantoni N, editors. In remembrance: archaeology and death. Westport, CT: Greenwood Publishing Company, 1997;51-63.

3. Mann RW, Owsley DW, Shackel PA. A reconstruction of 19th-century surgical techniques: bones in Dr. Thompson's privy. Hist Archaeol 1991;25(1):106-12.

4. Robbins LM. Hidden problems in identifying unknown skeletons in the Southeastern United States. In: Reichs K, editor. Forensic osteology: advances in the identification of human remains. Springfield, IL: Charles C. Thomas, 1986;24-32.

5. Jessee E, Skinner M. A typology of mass grave and mass grave-related sites. Forensic Sci Int 2005;152(1):55-9.

6. Juhl K, Olsen O. Societal safety, archaeology, and the investigation of contemporary mass graves. J Genocide Res 2006;8(4):411-35.

7. Equipo Argentino de Antropología Forense. Annual report: Guatemala collaborative agreement with the Guatemalan Forensic Anthropology Foundation, 1997; http://eaaf.typepad.com/pdf/1996_1997/10Guatemala 96_97.pdf (accessed March 27, 2013).

8. Equipo Argentino de Antropología Forense. Annual report: Guatemala, 2001; http://eaaf.typepad.com/pdf/2001/10Guatemala.pdf (accessed March 27, 2013).

9. Equipo Argentino de Antropología Forense. Triannual report: Paraguay, 2009; http://www.eaaf.org/eaaf_reports/2007-2009/AR09_p160_165_paraguay.pdf (accessed March 27, 2013).

10. Ferllini R, Croft AM. The case of an Armenian mass grave. J Hum Rights 2009;8(3):229-44.

11. Owsley DW, Strinovic D, Slaus M, Kollmann DD, Richardson ML. Recovery and identification of civilian victims of war in Croatia. CRM 1996;19:33-6.

12. Slaus M, Strinovic D, Pecina-Slaus N, Brkic H, Balicevic D, Petrovecki $\mathrm{V}$, et al. Identification and analysis of human remains recovered from wells from the 1991 war in Croatia. Forensic Sci Int 2007;171(1):37-43.

13. Slaus M, Strinovic D, Petrovecki V, Vyroubal V. Contribution of forensic anthropology to the identification process in Croatia: examples of victims recovered in wells. Croat Med J 2007;48(4):503-12.

14. York HP. Epilogue to war: unlikely graves in the wells, lakes, and caves of Bosnia-Herzegovina. Abstracts of the 11th Annual Meeting of the Midwest Bioarchaeology and Forensic Anthropology Association; 2004 October 29-30; Norman, OK. Indianapolis, IN: University of Indianapolis Archaeology and Forensics Laboratory, http://archlab.uindy.edu/documents/barfaa/BARFAA2004.pdf (accessed March 27, 2013).

15. Skinner MF. Hapless in Afghanistan: forensic archaeology in a political maelstrom. In: Ferllini R, editor. Forensic archaeology and human rights violations. Springfield, IL: Charles C. Thomas, 2007;233-65.

16. Hochrein MJ, McRoberts AL. Polar coordinate mapping and forensic archaeology within confined spaces. J Forensic Identif 2002;52(6):73349

17. Esiyok B, Balci Y, Ozbay M. Bodies recovered from wells, sewerage systems and pits: what is the cause of death? Ann Acad Med Singapore 2006;35:547-51.

18. Dogan KH, Demirci S, Erkol Z, Gulmen MK, Deniz I. Dead bodies found in wells. Am J Forensic Med Pathol 2010;31(3):208-12.

19. Magni PA, Borrini M, Dadour IR. Human remains found in two wells: a forensic entomology perspective. Forensic Sci Med Pathol 2013;9:413-7.

20. Ubelaker DH, Sperber ND. Alterations in human bones and teeth due to restricted sun exposure and contact with corrosive agents. J Forensic Sci 1988;33:540-6.

21. Levine LJ, Campbell HR, Rhine S. Perpendicular forensic archaeology. In: Rathbun TA, Buikstra JE, editors. Human identification: case studies in forensic anthropology. Springfield, IL: Charles C. Thomas, 1984;87-95.

Additional information and reprint requests:

Deren Ceker, M.Sc.

CMP Anthropological Laboratory (CAL)

Committee on Missing Persons in Cyprus (CMP)

Ledra Palace Hotel United Nations Buffer Zone

PO Box 21642

Nicosia 1590

Cyprus

E-mail: derenceker@hotmail.com 